\title{
Article \\ Clash Detection Using Building Information Modeling (BIM) Technology in the Republic of Kazakhstan
}

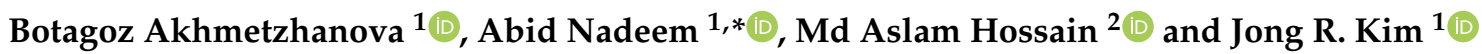 \\ 1 Department of Civil and Environmental Engineering, Nazarbayev University, Nur-Sultan 010000, Kazakhstan; \\ botagoz.akhmetzhanova@nu.edu.kz (B.A.); jong.kim@nu.edu.kz (J.R.K.) \\ 2 School of Engineering, Department of Civil Engineering, Monash University Malaysia, \\ Subang Jaya 47500, Malaysia; mdaslam.hossain@monash.edu \\ * Correspondence: abid.nadeem@nu.edu.kz
}

check for

updates

Citation: Akhmetzhanova, B.;

Nadeem, A.; Hossain, M.A.; Kim, J.R. Clash Detection Using Building Information Modeling (BIM) Technology in the Republic of Kazakhstan. Buildings 2022, 12, 102. https: / /doi.org/10.3390/buildings 12020102

Academic Editor: Jurgita Antucheviciene

Received: 18 November 2021

Accepted: 12 January 2022

Published: 21 January 2022

Publisher's Note: MDPI stays neutral with regard to jurisdictional claims in published maps and institutional affiliations.

Copyright: () 2022 by the authors Licensee MDPI, Basel, Switzerland. This article is an open access article distributed under the terms and conditions of the Creative Commons Attribution (CC BY) license (https:// creativecommons.org/licenses/by/ $4.0 /)$.

\begin{abstract}
Research on the digital built environment in the context of identifying and minimizing clashes is a critical area to investigate owing to the significant influence of clashes on the construction process. This research aims to identify the current state of building information modeling (BIM) enabled clash detection in the architecture, engineering, and construction and operation (AECO) industry of the Republic of Kazakhstan. It further identifies the main reasons for clash occurrence, methods, and practices used to decrease the workload on BIM project teams. It also recognizes the existence of BIM departments (their type and functionalities). It aims to answer whether the transition from clash detection to clash avoidance is possible in a country where BIM technology has just penetrated. This research conducted a literature review and review of current regulatory documents regarding BIM technology, interviews with industry professionals, and a survey among construction companies and design organizations. Although the AECO industry of Kazakhstan has just entered the BIM environment, this research has shown that BIM-enabled clash detection and resolution processes are trying to evolve in parallel. It was concluded that the transition is difficult in a country where document assistance with clash detection and resolution is not well developed.
\end{abstract}

Keywords: BIM technology in Kazakhstan; clash detection; reasons for clash occurrence; BIM departments

\section{Introduction}

One of the biggest concerns in construction projects is clashes and their early identification. Manual identification of clashes is time-consuming and requires the synthesis of exceptional design skills and experience. Digital technology, known as building information modeling (BIM), assists design professionals and contractors in simulating a digital space before construction has begun with an information database [1]. It helps to prevent and solve clashes before they emerge on construction sites using but not limited to personal computers. Pärn et al. [2] defined 'clash' equivalently to 'collision' or 'conflict', because both mean positioning errors where elements overlap when connected. This research does not distinguish or separate these terms.

According to Chahrour et al. [3], clashes appear as a result of falling design rules, design errors, design uncertainty, model inaccuracy, and tolerance. Based on detecting clashes through BIM tools, there are two general types of clashes: relevant and irrelevant. However, the classification of clashes in the literature has various forms (Table 1).

If clashes lead to productivity loss, interruptions, and rework, they are relevant in the project [4]. Therefore, relevant clashes are the clashes that need to be resolved. In contrast, irrelevant clashes do not need resolution, as they can be one error repeated many times throughout the project or intentionally created clashes [2].

Considering that thousands of clashes might be caught in some projects via specialized software [4], proper identification of clashes, including relevant and irrelevant clashes, and the appropriate allocation of clash resolution among BIM project teams have an important 
role. BIM technology allows cross-disciplinary collaboration and development to exchange and advance data transfer among project participants. However, to use BIM technology to its full potential, open standards, protocols, and tools must be developed and integrated [5]. Even if BIM has valuable functions, the project delivery time still suffers [6]. The time to resolve design clashes might be almost equal to the conventional manual procedure because of nonvalue-adding steps. In countries where BIM technology just started to be integrated, documental assistance and team coordination, which would avoid non-value-adding steps, correctly line up working processes are significant.

Table 1. Clash classification in the literature.

\begin{tabular}{|c|c|c|}
\hline Source & Clash Classification & Description \\
\hline [2] & $\begin{array}{l}\text { (i) Error } \\
\text { (ii) Pseudo } \\
\text { (iii) Deliberate } \\
\text { (iv) Duplicate }\end{array}$ & $\begin{array}{l}\text { (i) a fault clash that must be found and resolved; } \\
\text { (ii) acceptable clashes without the need to be resolved; } \\
\text { (iii) intentionally created clashes; } \\
\text { (iv) repeated clashes throughout the model. }\end{array}$ \\
\hline [3] & $\begin{array}{l}\text { (i) Major } \\
\text { (ii) Medium } \\
\text { (iii) Minor }\end{array}$ & $\begin{array}{l}\text { (i) participation of client team, designer, and the contractor requires the client's approval; } \\
\text { (ii) involvement of the contractor, requires the approval of the designer; } \\
\text { (iii) involvement of the contractor, no approval requirements by the designer or the client. }\end{array}$ \\
\hline [7] & $\begin{array}{l}\text { (i) Soft } \\
\text { (ii) Hard }\end{array}$ & $\begin{array}{l}\text { (i) violation of clearance or interference between design details and access space; } \\
\text { (ii) physical interferences between components. }\end{array}$ \\
\hline [8] & $\begin{array}{l}\text { (i) Soft } \\
\text { (ii) Hard } \\
\text { (iii) Time }\end{array}$ & $\begin{array}{l}\text { (i) components that are excessively close in the distance; } \\
\text { (ii) penetration of one building component into another; } \\
\text { (iii) spatial challenges expected during constructability and operability. }\end{array}$ \\
\hline
\end{tabular}

'Kazakh Scientific Research and Design Institute of Construction and Architecture' (KazSRICA) joint-stock company (JSC), which first initiated the adoption of BIM in Kazakhstan in 2015, developed 12 regulatory documents on BIM in Kazakhstan after the publication of the action plan in 2017 (Figure 1). These 12 regulatory documents define principles and requirements for the information management process, including the creation of an information model, its use, as well as the conditions for the exchange and storage of data, among others. It gives information for all stakeholders in the development and implementation of investment projects for the construction of facilities using BIM technology at the expense of public investment in construction and funds of subjects of the quasi-public sector. KazSRICA JSC also leads the Commission for the development of scientific and technical documentation in the field of information modeling under the Basic Organization of the Commonwealth of Independent States (CIS) member states.

Obtaining feedback from the industry is a well-established practice for developing and updating standards. However, there was no industry feedback-based investigation for this regulatory framework, along with the use of BIM-enabled clash detection by construction companies and design organizations. The summary of previously conducted research on BIM technology in Kazakhstan is presented in Table 2. 
2017-2018 (8 standards)

2019 (4 standards)

\begin{tabular}{|c|c|c|c|c|}
\hline CONCEPTION & PROJECT & EXPERTISE & CONSTRUCTION & OPERATION \\
\hline \multicolumn{5}{|c|}{1 - GDC RK. The basic provisions } \\
\hline \multicolumn{5}{|c|}{2 - CR RK. Common data environment } \\
\hline \multicolumn{5}{|c|}{3 - CR RK. Life cycle of construction objects. The basic terms } \\
\hline \multirow{3}{*}{$\begin{array}{l}4 \text { - CR RK. Life cycle of } \\
\text { construction objects. } \\
\text { The requirements for } \\
\text { information models at } \\
\text { the stage of pre-design } \\
\text { preparation of } \\
\text { construction }\end{array}$} & $\begin{array}{l}5 \text { - CR RK. Life cycle } \\
\text { of construction ob- } \\
\text { jects. The require- } \\
\text { ments for informa- } \\
\text { tion models at the } \\
\text { stage of design prepa- }\end{array}$ & $\begin{array}{l}7 \text { - CR RK. The } \\
\text { procedure for the } \\
\text { examination of } \\
\text { information models }\end{array}$ & $\begin{array}{l}9 \text { - CR RK. Life cycle of } \\
\text { construction objects. } \\
\text { The requirements for } \\
\text { information models at } \\
\text { the construction stage }\end{array}$ & $\begin{array}{l}11 \text { - CR RK. Life cycle } \\
\text { of construction objects. } \\
\text { The requirements for } \\
\text { information models at } \\
\text { the operational stage }\end{array}$ \\
\hline & ration of construction & & \multirow{2}{*}{$\begin{array}{l}10 \text { - CR RK. The } \\
\text { application of } \\
\text { Building Information } \\
\text { Modeling in a } \\
\text { construction } \\
\text { organization }\end{array}$} & \multirow{2}{*}{$\begin{array}{l}12 \text { - CR RK. The } \\
\text { application of } \\
\text { information modeling } \\
\text { in the operating } \\
\text { organization }\end{array}$} \\
\hline & $\begin{array}{l}\text { 6-CR RK. The } \\
\text { application of infor- } \\
\text { mation modeling in } \\
\text { a design } \\
\text { organization }\end{array}$ & & & \\
\hline
\end{tabular}

8 - GDC RK. The requirements for registration of design documentation

Figure 1. The regulatory framework for the use of BIM technology in Kazakhstan (adapted from [9]). Guiding documents in the construction (GDC) in the Republic of Kazakhstan (RK), Code of rules (CR) of the Republic of Kazakhstan (RK).

Table 2. Conducted research on BIM technology in Kazakhstan.

\begin{tabular}{llllll}
\hline Source & Year of Study & \multicolumn{1}{c}{ Research Objectives } & Methodology & \multicolumn{1}{c}{ Participation } & \multicolumn{1}{c}{ Results } \\
\hline [10] 2016 & $\begin{array}{l}\text { The state of BIM use in the } \\
\text { Kazakhstan construction } \\
\text { industry }\end{array}$ & Online survey & $\begin{array}{l}120 \text { (34 responses } \\
\text { collected) industry } \\
\text { professionals }\end{array}$ & $\begin{array}{l}\text { BIM is not widely adopted } \\
\text { because of the unfamiliarity of } \\
\text { construction industry members }\end{array}$ \\
\hline [11] 2020 & $\begin{array}{l}\text { Identification of } \\
\text { opportunities and barriers } \\
\text { of implementing BIM } \\
\text { in Kazakhstan }\end{array}$ & $\begin{array}{l}\text { Online survey, } \\
\text { interviews }\end{array}$ & $\begin{array}{l}100 \text { (46) } \\
\text { companies- } \\
\text { online survey; } \\
2 \text { interviews }\end{array}$ & $\begin{array}{l}\text { The adoption of BIM in } \\
\text { Kazakhstan is very low; lack of } \\
\text { clear guidelines to implement } \\
\text { BIM; a high potential of BIM in } \\
\text { Kazakhstan }\end{array}$ \\
\hline [12] 2020 & $\begin{array}{l}\text { Level of BIM development } \\
\text { and application } \\
\text { in Kazakhstan }\end{array}$ & Online survey & $\begin{array}{l}550 \text { (132) } \\
\text { construction } \\
\text { companies }\end{array}$ & $\begin{array}{l}\text { The wide use of software from } \\
\text { Autodesk; BIM used mostly for } \\
\text { multi-family residential buildings; } \\
\text { many companies are planning to } \\
\text { adopt BIM }\end{array}$ \\
\hline
\end{tabular}

This research aims to determine the current state of BIM-enabled clash detection in Kazakhstan. The main questions of this research are as follows: (i) How well is BIM-enabled clash detection used in the architecture, engineering, and construction and operation (AECO) sector of Kazakhstan? (ii) What are the main reasons for clashes identified through BIM tools in Kazakhstan? (iii) What kinds of methods and practices are used to decrease the load on BIM project teams during clash detection? (iv) What kind of transition should be done to move from clash detection to clash avoidance? Is this transition possible in a country where BIM technology has just started to penetrate?

\section{Review of the Literature}

The importance of proper design has been highlighted in almost all of the research done so far. Ciribini et al. [13] suggested that the improvement of modeling accuracy would help clash detection. However, it would significantly increase the modeling effort by project teams. Methods to simplify and optimize the work of BIM project teams during conflict control have not been well investigated. Pärn et al. [2] stated that twentieth- 
century management practices hold back innovative digital technologies of the 21st century. Therefore, it is essential to investigate how to optimize the work of the BIM project teams. Furthermore, Pärn et al. [2] proposed to convert the management of clash detection into the digital environment, investigate deeper resolution processes, and manage the influence on the distribution of design clashes.

However, most of the research focused on the development of detection algorithms $[14,15]$, the use of historical information in the development of clash detection $[16,17]$, and machine learning (ML) [18]. However, as Pärn et al. [2] noted, despite all the possibilities ML has given to the AECO sector, such as automation of rule checking within BIM, a control by 4D BIM, clash detection still requires much time and labor intervention. It is still mechanistic, which means that a BIM manager must scan and analyze each clash of its type. In interviews conducted by Lin and Huang [19] with senior project managers, it was revealed that clash reports were reviewed selectively or neglected entirely by BIM managers in Taiwan because of the extreme consumption of time to evaluate clashes. Moreover, Pärn et al. [2] highlighted the urgent need for automated methods, excluding manual intervention and creating clash detection profiles. The following section will discuss previous research carried out to automate the process by removing manual intervention by filtering clashes.

Additionally, Pärn et al. [2] raised the problem of file formats exchanged with software. They stated that the AECO industry, with its industry foundation classes (IFCs), which were supposed to cover this issue, is not well done in information exchange. The necessary data could vanish when files are exchanged through software. However, Nawari [20] highlighted that building regulations and codes might be checked automatically because BIM created a new condition for it. It was summarized that BIM technology improves the accuracy and the efficiency of checking processes for three parties: the government, designers, and local agencies. Previous research on the topic of IFC will also be discussed.

\subsection{Filtering Irrelevant Clashes Using BIM Tools}

A debate has arisen on the use of BIM to detect clashes as it shows significant and irrelevant clashes that do not substantially influence them. Therefore, project team members cannot focus on the project design's more sensitive aspects, as unrelated clashes require time to regard each clash one by one. Minimization of the influence of irrelevant clashes on the project is a key purpose of the prediction of clash relevance. Pärn et al. [2] suggested using model parameters such as log logistic three parameter (3P) and generalized gamma distribution to predict similar clashes that accurately estimate the time and resources required to integrate the BIM model for the project team. They concluded that the mitigation of clashes depends on the understanding of tolerances that reduce unnecessary clashes.

$\mathrm{Hu}$ et al. [4] suggested using network analysis that considers component dependency to develop clash detection to eliminate extra work because of irrelevant clashes that decrease the precision and help project teams. Nevertheless, Lin and Huang [19] highlighted that the acquisition and maintenance of the rules during the construction of dependency relationships between items and query algorithms require not only considerable time but also intensive labor intervention. In the research done by $\mathrm{Hu}$ and Castro-Lacouture [18], the automatic distinction between relevant clashes and irrelevant clashes was made through machine learning algorithms. Six types of algorithms were compared on the example of an actual three-story building with a total gross floor area of approximately $3000 \mathrm{~m}^{2}$ by classification of informative attributes. Using the Kruskal-Wallis test, the Jrip-based rule method was superior to naïve Bayes, binary logistic regression, random forest, Bayesian network, and 48-based decision tree. According to the authors, even if the suggested model shows $80 \%$ prediction accuracy, the need to check each clash before coordination meetings disappears manually. It is only limited to data size and the data collection process's automation level. The issue of collecting insufficient data resulting in insufficient prediction accuracy of ML was underlined by Lin and Huang [19]. Their study combined two techniques of rule-based reasoning and supervised ML to develop an algorithm that would filter out irrelevant clashes from clash detection reports generated from BIM software. 
The use of a hybrid method resulted in increased prediction accuracy of ML. However, Akponeware and Adamu [5] stated that algorithms for irrelevant clashes would not mitigate the situation. Therefore, it can be concluded that the debate that arose requires more cases to run and more clash reports to be analyzed.

\subsection{Industry Foundation Classes (IFC) as a Data Exchange}

Industry foundation classes (IFCs), which were supposed to cover data interoperability, might fail. However, Van Den Helm et al. [14] stated that the IFC structure could develop precision of collision detection. Nawari [20] stated that IFC is a key to facilitate interoperability in a cost-effective way and it enables to exclude dependence on a particular file format. IFC is an interoperable standard that helps interpret and illustrate buildings' and structures' geometry with related information without any obstacles in exchange, not depending on the geography or market [21]. It can be compared with hypertext transfer protocol (HTTP) and hypertext markup language (HTML), which makes the internet coding open to all who know how to use it. Thus, individuals can transfer information with each other anytime, without depending on the receiver and a sender's location. Lévy and Ouellette [21] identified the following IFC privileges: openness, neutrality, and non-proprietary. IFC might be regarded as a language for designers, engineers, and software developers.

Pärn et al. [2] stated that experiential learning is not protected because organizational learning is insufficient. It can be seen from identification and resolution made by the project management team (PMT) within a compressed time rather than the attempts of PMT members to study clash occurrence and its mitigation. The problem of clash detection software is that it is not fully automated; thus, it depends on the BIM manager or BIM coordinator, who checks the given clash data, making this process costly and labor-intensive analysis obligatory. Previous research on cost-benefit analysis of clash detection using BIM technology will be discussed in the following paragraph. The clashes might reach several tens of thousands of necessary observations depending on the project type, which means that PMT's approach is cumbersome. Moreover, the authors identify PMT members as separately working individuals who do not negotiate with each other using BIM software. Thus, this tendency of fragmented teams might be found in each country's organization, including Kazakhstan. IFC was supposed to solve the issue of interoperability, but IFC itself contains errors [2]. Nevertheless, IFC is not just one standard in which the AECO sector works on interoperability. The Construction Operations Building Information Exchange (COBie) and the BIM Project Execution Planning Guides for Project Delivery teams and Facility Owners are also available. However, their applicability needs to be investigated more profoundly. Therefore, the best interoperable standard that suits companies needs to be found.

The use of clash control tools has many advantages. Staub-French and Khanzode [7] summarized the impact of 3D and 4D technologies on coordination and construction sequence. However, no justification would be well documented for the cost savings of clash detection via BIM tools. Charour et al. [3] stated that their research could use the Jripbased rule method proposed by $\mathrm{Hu}$ and Castro-Lacouture [18]. However, Charour et al. [3] focused on proving how BIM technology's clash detection leads to cost savings. It was found, based on the multimillion-dollar project case study, that the cost savings of contract value reached twenty percent.

Moreover, the proposed schema makes the categorization of clashes simpler. This schema proposed by Charour et al. [3] could be used by any organization as there are no limitations to prove that BIM-enabled clash detection is beneficial. Nevertheless, it is crucial to understand the main reasons for clash occurrence for each organization that applies BIM technology.

The literature identifies the following reasons for design errors: time constraints during the design stage, the complexity of design objects [8], the use of 2D rather than 3D [22], poor management [23], traditional human resource practices [24], and lack of qualified specialists [25], among others. Three-dimensional clashes occur in mechanical, electrical, 
and plumbing (MEP) systems owing to the isolated working of team members, which is found to be the main cause of the high number of clashes in the research carried out by Akponeware and Adamu [5]. They argued that cloud-based typical data environments (CDEs) are supposed to aid clash avoidance in creating isolated working from the beginning of the design stage. This research will investigate how BIM team members of organizations in Kazakhstan communicate with each other, whether via specialized company platforms, emails, or within the software, and whether CDEs are used. As there was no research on clash detection and resolution in Kazakhstan, this research will identify reasons for clash occurrence based on the experience of construction and design organizations.

\section{Methodology}

The methodology for this research consists of the following stages:

Stage 1A: Literature review

This stage includes a review of the literature regarding BIM technology for clash detection, clash resolution, and project management in the BIM environment. The latest research papers were the subject of the search. The review should find the main reasons for the high occurrence of clashes in BIM software, mitigation, and/or elimination methods.

Stage 1B: Meetings with industry professionals

This stage intends to find possible existing gaps by visiting the industry. The questions regarding difficulties faced during the working process in the BIM environment and the hypothesis formed during the literature review were examined. For that, the BIM department of one construction company was selected. The selection criteria were based on company size and its role in the integration of BIM technology in Kazakhstan. The highest position in the department (the head of the BIM department) was interviewed. More information regarding the company and interviewee could not be given to keep the company-specific information confidential. The names of a construction company and design organization are also not revealed in the article so as to maintain confidentiality.

Stage 1C: Review of the regulatory documents related to BIM technology in Kazakhstan

This stage includes a review of regulatory documents related to BIM technology in Kazakhstan. It includes guiding documents in the construction (GDC) and code of rules (CR), making up, in total, twelve regulatory documents developed by the KazSRICA JSC (Figure 1). This review is intended to obtain more knowledge about current regulations and to find inconsistencies that were criticized by industry professionals.

Stage 2A: The questionnaire (Supplementary Materials) for construction companies and design organizations

The online survey (Supplementary Materials) was conducted using the Google forms platform for its convenience in collecting and analyzing responses. It was prepared in the Russian language and sent to construction companies and design organizations. The survey was prepared to identify the following aspects:

- Approximate time when construction companies and design organizations started to use BIM;

- The purpose of BIM usage;

- The types of regulatory documents that govern the work of the BIM departments (if such exists);

- The size and nature of BIM departments (if such exists);

- The average number of projects that are currently being modeled using BIM technology;

- The ways in which team members worked before the COVID-19 pandemic;

- The ways in which team members inform each other about collisions;

- The attitude of industry professionals towards "collision detection" or "collision avoidance";

- The main causes of collisions in BIM; 
- The place where clashes occur most of the time;

- Conducting meetings/brainstorming sessions where decisions are made to resolve collision issues and their frequency;

- The possible strategies that would be effective;

- The ways of observation of information security during collaborative design;

- The ways in which the work on collisions is distributed among team members.

Survey responses were monitored by email, telephone calls, personal visits, and LinkedIn contacts. The survey results were studied and presented using descriptive statistics.

Stage 2B: Interviews with the heads of KazSRICA JSC and construction companies

This research was based on a review of the literature and industry needs to be obtained through a pilot interview. After collecting responses to the survey from construction companies and design organizations, the interview with the KazSRICA JSC was conducted. This sequence is made to determine the number of construction companies that follow the regulatory documents made by this institute and the weaknesses encountered. The list of interviewees is presented in Table 3. One interview with one company that does not use BIM technology was also conducted to know why they are not yet adopting BIM technology.

Table 3. List of interviewees.

\begin{tabular}{cccccc}
\hline$\#$ & Organization Type & Job Title of Interviewees & Interview & Duration, h & BIM Use \\
\hline $1 \mathrm{a}$ & Research and design institute & The head of the information modeling center & 1 & 1.5 & Yes \\
\hline $\begin{array}{l}2 \mathrm{~b} \\
\mathrm{c}\end{array}$ & Construction company & The heads of the BIM department & 2 & 3 & Yes \\
\hline $3 \mathrm{~d}$ & Construction company & $\begin{array}{c}\text { The head of the production and } \\
\text { technical department }\end{array}$ & 1 & No \\
\hline & & Total (4) & Average (1.4) \\
\hline
\end{tabular}

Stage 3: Data collection and analysis

The data source summary for the research is presented in Figure 2. Descriptive statistics were used to analyze the online survey data. The results of the five-point Likert scale questions were checked for Cronbach's alpha coefficient via MS Excel for reliability and internal consistency. The Shapiro-Wilk test was used to analyze the normal distribution of data obtained from the questionnaire, using SPSS software. Kendall's coefficient of concordance was also calculated to identify the general agreement among the survey participants about the rankings. To identify the mean scores' significance levels, whether the calculated values are statistically significant, a one-sample t-test was calculated via SPSS Statistics software. The interview results were analyzed and compared with the online survey.

\section{Stage 4: Conclusion}

This stage discusses the results and gives some recommendations. Countries that started to integrate BIM technology might refer to recommendations set up by this research based on the Kazakhstani experience. 


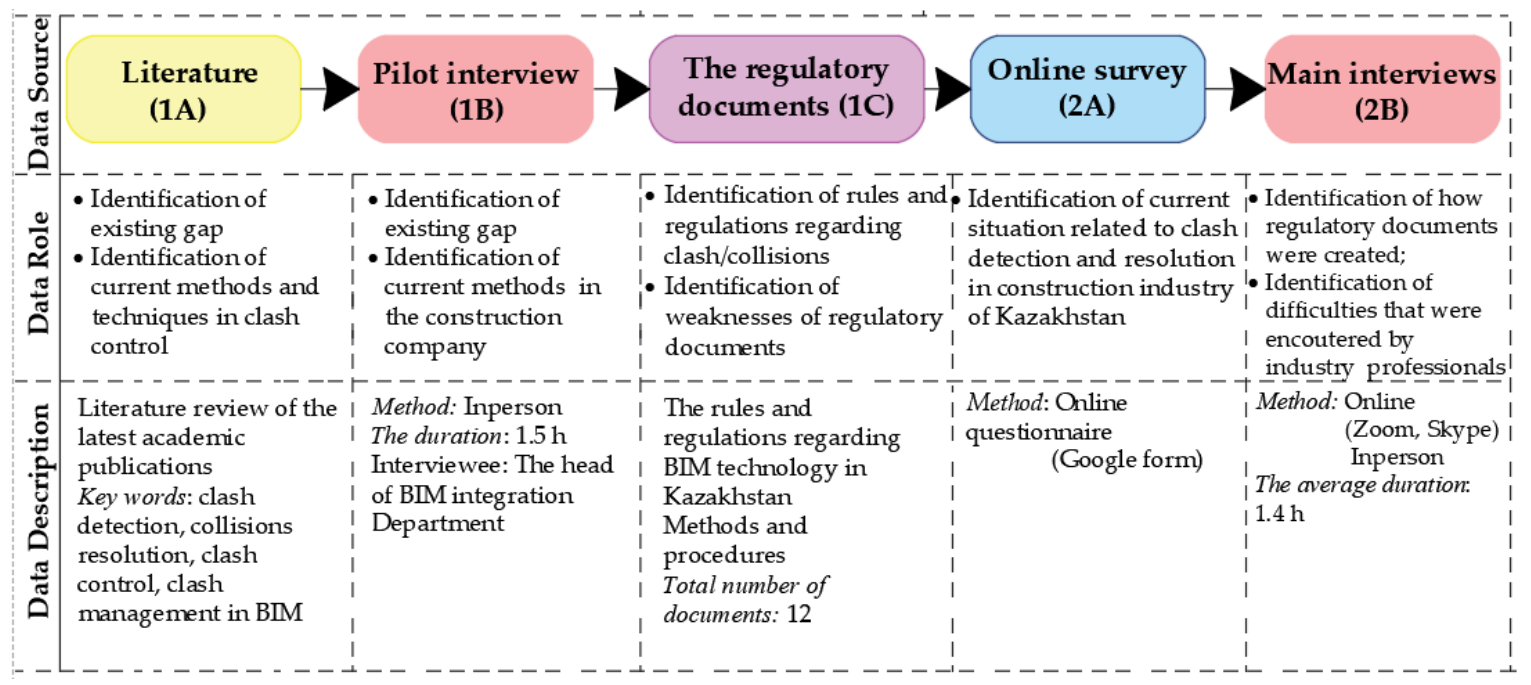

Figure 2. Data source summary.

\section{The Results of an Online Survey-Stage 2A}

In this research, an online survey was prepared and sent to 182 randomly selected construction companies and design organizations of all cities of Kazakhstan. The companies and organizations focus on the construction of different facilities. A total of 58 answers were received. To communicate directly with industry professionals, the social network "LinkedIn" was used. However, most of the respondents preferred to stay anonymous. The following professions were in search:

- BIM specialist;

- BIM coordinator;

- Architect, architectural technician;

- Civil designer, design engineer, design coordinator.

\subsection{BIM Technology in Kazakhstan: BIM Departments, BIM Workflow, BIM Documentation}

BIM technology began to be integrated into the Republic of Kazakhstan's construction industry at the state level in 2017. For that reason, there was a distinction (before 2017 and 2017-2020) in the survey question. Based on the survey results, it was evident that BIM technology mostly started being used in the recent three years (59\%); the share of BIM implementation before 2017 was $41 \%$.

In the survey done by Tatygulov et al. [12], 28 companies' responses regarding BIM utilization were collected. Almost $40 \%$ responded that BIM was used in companies for more than five years, and $25 \%$ used it for about three to five years. Therefore, there are some experienced companies in Kazakhstan, but their number in terms of the entire country is insignificant.

As this research focuses on managing work within BIM departments, it is important to identify such departments and their functionalities. Furthermore, to know whether construction companies and project design organizations emphasize the importance of BIM in their organizational structure, the question of the existence of a BIM department was investigated. It was found that more than half of the companies and organizations (53\%) have a BIM department. The answers of six respondents who did not indicate the presence of a BIM department were counted as no BIM department. The next question in the survey was about the number of employees. It was found that more than half $(59 \%)$ of the departments where BIM is used have employees not exceeding ten people, $26 \%$ of respondents indicated that are "more than ten people", $10 \%$ of respondents selected "from 25 to 50 ", and only $5 \%$ of respondents indicated that there are "more than 50 " employees in the department. It can be concluded that most of the participating companies and organizations wherein BIM is used are small enterprises. 
As found by Akponeware and Adamu [5], the work in isolation of team members is the main reason for collisions in BIM MEP systems. The survey results revealed that even with the majority of companies working in "open space" $(53 \%), 35 \%$ of respondents indicated that they worked in isolation from each other, and more than one-tenth (12\%) worked in a building where team members work in both "open space" and "isolation from each other".

A question was prepared to know whether the BIM departments are interdisciplinary or multidisciplinary (Figure 3). Based on the survey result, 21\% of BIM departments are multidisciplinary, while the share of interdisciplinary departments is only $10 \%$.

\section{Which statement is more appropriate for your department?}

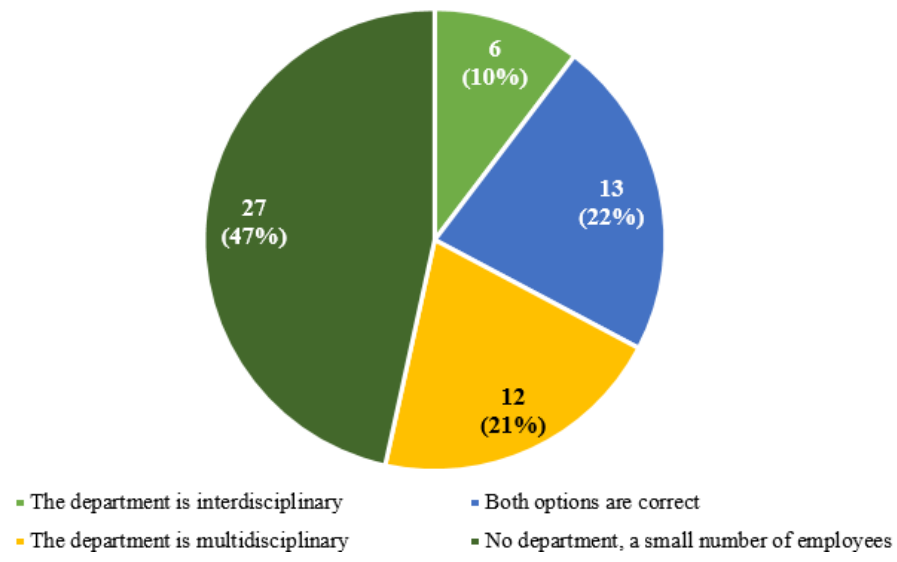

Figure 3. The types of BIM departments.

Eighty-three percent of the companies were found to have fewer than ten projects being modeled using BIM technology. Seven construction companies/design organizations have between 10 and 25 projects being modeled, and only three companies work on more than 25 projects via BIM tools.

The survey determined that construction companies and design organizations use BIM technology to model and visualize buildings and structures most of the time. However, more than half of the companies use BIM for calculation and analysis, and exactly half of the companies use BIM for collision coordination (Figure 4). The use of BIM to model steel structures, calculate the volume of materials (analysis of material need), and for maintenance and operation was recorded in the 'Other' section.

\section{BIM technology in your company is mainly used for}

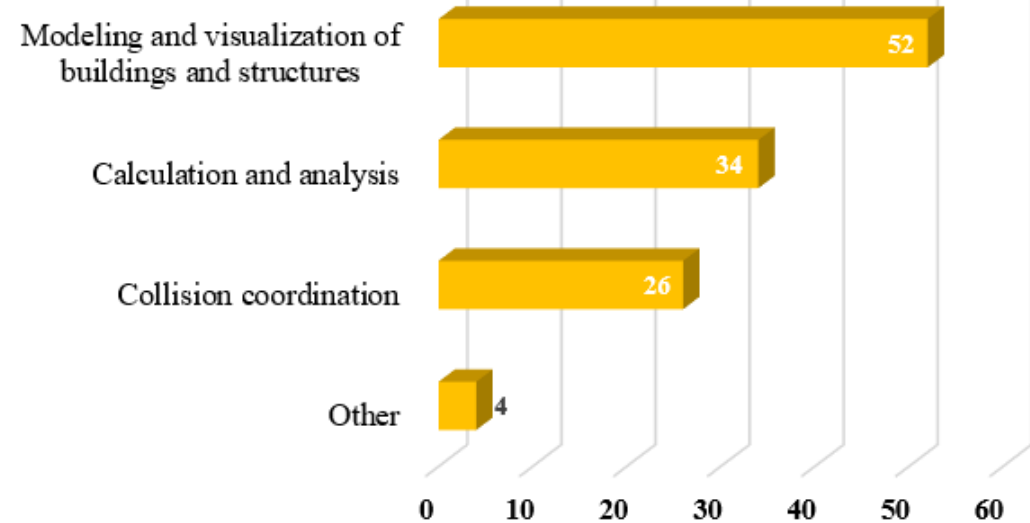

Figure 4. BIM utilization in construction companies and design organizations. 
During interviews with construction companies, it was observed that companies criticize the current Building Construction Rules and Requirements (BCRRs) of the RK regarding BIM technology. To ascertain the current situation following BCRRs, the regulatory documents that govern the work on BIM technology were investigated (Figure 5).

\section{What regulatory documents govern the work on BIM technology?}

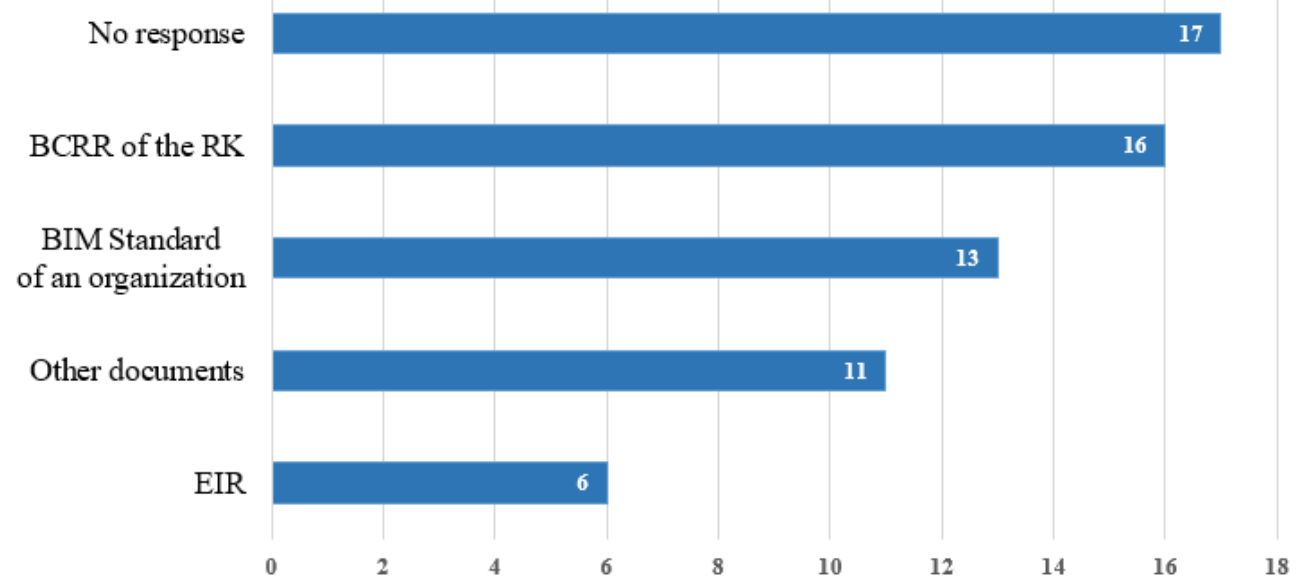

Figure 5. The regulatory documents in construction companies and project design organizations that control the work on BIM technology.

Most of the respondents did not answer the question; some respondents specified that they do not use any: sixteen companies out of fifty-eight use the BCCRs of the RK. Six companies follow Exchange/Employer Information Requirements (EIRs). As this question was an open text question, multiple responses were collected. The section of "other" companies and organizations highlighted the use of Publicly Available Specifications (PASs) such as PAS 11922 2013, PAS 11923 2014, UK BIM Protocol Version 2, BS 1192, and Euro codes. It was noted by companies that the current regulatory framework does not correspond to the desired quality.

\subsection{The Main Reasons for Clash Occurrence in the BIM Environment in Kazakhstan}

It is essential to know the main reasons for clashes in the BIM environment that Kazakhstan industry professionals face during working processes. The five-point Likert scale question was prepared in which the respondent had to rate nine given possible reasons (A-using different file formats [26]; B-modelling errors [8]; C-using 2D rather than 3D [22]; D-lack of qualified specialists [25,26]; E-lack of time [8]; F-communication problems between team members [2,5]; G-lack of information on BIM technology within the company (research hypothesis); H-insufficient object model information [8]; and I-the complexity of the objects [8]) in which a scale 1 indicated the main reason and a scale 5 represented a secondary reason. It was checked for Cronbach's alpha coefficient via MS Excel. Cronbach's alpha coefficient helps to assess the reliability and internal consistency of summated rating scales [27]. It ranges from 0 to 1 , where values greater than 0.7 represent the reliable scale used for the measurement [28]. The value obtained was 0.897 , which is a high indication of reliability and internal consistency among all nine items.

The normal distribution of data obtained from the questionnaire was analyzed by the Shapiro-Wilk test [29] via the software named SPSS statistics. Each item was calculated for sig. value. If the value is less than 0.05 , the data are regarded to be not normally distributed. Based on the test of normality calculated by SPSS Statistics software, sig. values were found to be less than 0.05 , which indicated that the data were not normally distributed. However, as the data are often non-normally distributed, the mean scores of the items are taken for ranking the items, and it is regarded to be reliable. In this case, if the mean score were 
the same, the factor with a higher standard deviation would be ranked below. The main reasons for clashes in BIM tools that construction companies and design organizations encountered are as follows (from main to secondary):

1. Using different file formats;

2. Lack of time;

3. Insufficient object model information;

4. The complexity of the objects;

5. Modeling errors;

6. Lack of information on BIM technology within the company;

7. Using $2 \mathrm{D}$ rather than $3 \mathrm{D}$;

8. Communication problems between team members;

9. Lack of qualified specialists.

Kendall's coefficient of concordance was calculated to identify the general agreement among the survey participants about the rankings, where the value ranges from 0 to 1 in increasing order of agreement [30]. The test in the SPSS Statistics software was equal to 0.085, which shows the respondents' agreement on the rankings. To identify the mean scores' significance level, whether the calculated values are statistically significant (values should be less than 0.05), one sample t-test will be calculated. The population means were determined by obtaining the value between the lower and upper bound with 95\% confidence for each of the nine items separately. The result showed that the calculated values are not statistically significant.

The next Likert scale question focused on where collisions occur, that is, whether in MEP systems, heating, ventilation, and air conditioning (HVAC) systems, or structural objects. Cronbach's alpha coefficient was found via MS Excel to be equal to 0.865, which is a high indication of reliability and internal consistency among all three items. Data were found to be not normally distributed, which is frequently the case. Therefore, based on the results taken from SPSS, the place where collisions most often occur during working in the BIM environment in the experience of Kazakhstani construction companies and design organization is in structural objects. The next place is in HVAC systems. The least is in MEP systems. Kendall's coefficient of concordance was 0.027 , which shows less agreement on the rankings among survey participants. The one sample t-test revealed that values are not statistically significant.

\subsection{BIM Technology in Kazakhstan: Coordination Meetings, Strategies to Improve Clash Detection, Data Security, Collision Distribution among Team Members}

It was important to know whether coordination meetings are made on clash resolution and their frequency. The survey has shown that seventy-six percent of respondents have meetings/brainstorming sessions to discuss clashes. However, almost a quarter do not conduct especially dedicated meetings for resolution decisions on clashes. However, in the next question regarding the frequency of meetings conducted, only ten companies answered no meetings. In comparison, there were responses where meetings were conducted only if necessary or when collisions were observed and grouped under "if noticed" (Figure 6). The answers of three respondents, who did not answer, were counted as no meetings.

Most of the respondents $(66 \%)$ found that it is more important to achieve better avoidance of conflicts rather than better detection of conflicts (17\%). Another seventeen percent of the respondents did not separate these options. 


\section{Frequency of conducted meetings/brainstorming sessions}

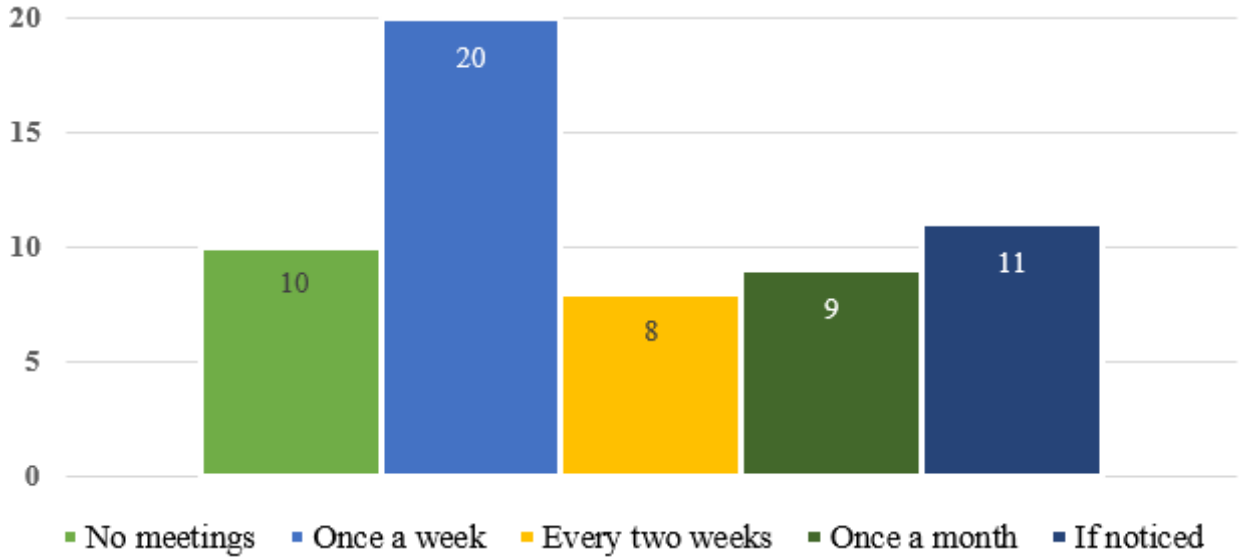

Figure 6. Frequency of meetings/brainstorming sessions.

Kazakhstan's construction companies and design organizations were asked to give their suggestions or strategies to improve current collision detection. The question was 'long answer text', which means different answers were collected. Nevertheless, similar meaning answers were grouped under the same category. The following suggestions and strategies were recorded:

- The architectural design must be of as high quality as possible and systematically checked for clashes, which means that the federated model should be united every day if possible;

- Young specialists should undergo practical training directly at the construction site. Moreover, team members should study foreign practices and raise the level of automation. The agile methodology is recommended to be followed;

- $\quad$ The guide or rules for designers should be created and followed;

- The priority to solve collisions should be set;

- The database should be regulated;

- A strong well-coordinated team should be gathered, and a special reporting system should be developed if possible. There should be more communication between all project participants in key design stages;

- There should be a BIM coordinator/manager.

Twelve companies indicated the need for educational courses or training for team members. One company stated that there is no way to improve it because it is a working process. However, almost all representatives of companies and organizations highlighted that each item is connected, and the well-coordinated joint work and communication of team members have the most important role in developing conflict detection.

Three possible strategies were suggested from which to choose: educational courses and training for team members, improving collision detection algorithms, and improving coordination in a shared data environment. The share of each of the last two strategies was almost similar (29\% and 30\%) and educational courses and personnel training were regarded as the most effective strategy $(41 \%)$ by respondents.

How information security is observed in a collaborative design was an open-text question. Collected similar answers were grouped into the following categories, as shown in Figure 7. It was found that almost half of companies and organizations do not have an observation of information security during collaborative design. If the question was skipped, it was regarded as "No observation". One-tenth of the respondents specified the use of protected common data environments (CDEs), while nine percent indicated the 
use of special software. The use of personal identification with a passcode and electronic signature took the lowest share, at seven percent and four percent, respectively.

\section{How is information security observed in a collaborative design?}

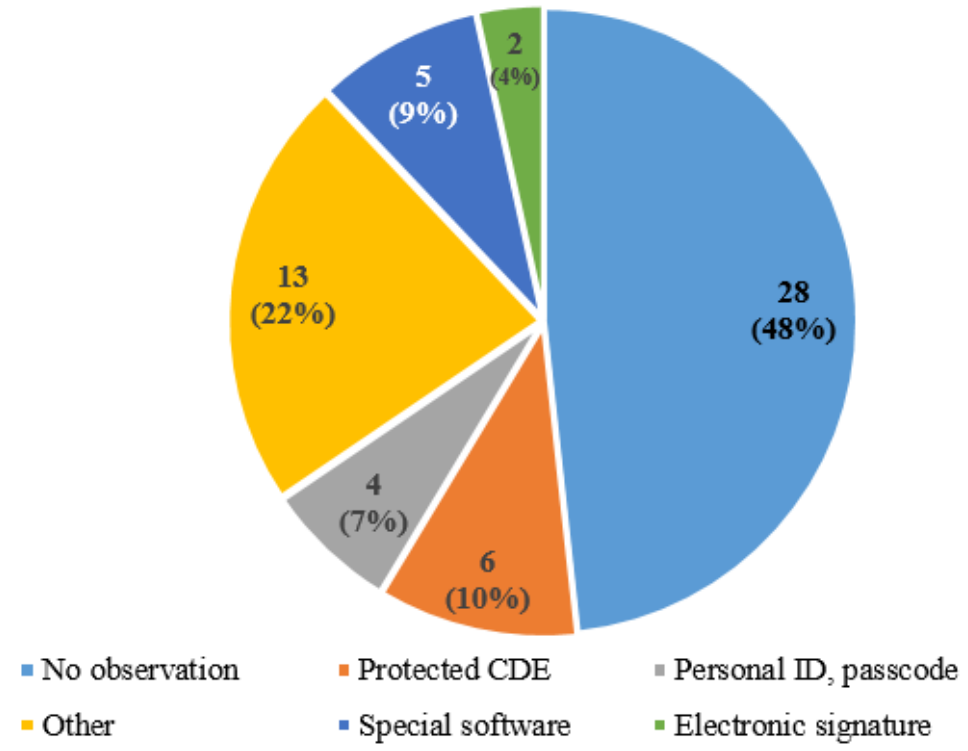

Figure 7. Observation of information security in a collaborative design.

For the 'other', the following answers were grouped because they could not follow a pattern. The direct translation of these answers: 'Regulated by document flow', 'We do not use email', 'The insertion of plugins according to which access is issued to users', 'All details must be written in the BIM standard', 'When working together, the issue of security is very acute', 'by Working sets', 'from the head of the department', 'the trust', 'It is prescribed in the contract'. There are no real instruments', and 'Obligations of nondisclosure', among others. The software BIM 360 was highlighted as the best option to observe information security by one company, and the Ios platform helps another company monitor information security.

In construction companies and design project organizations, it has been found that email for information exchange and specially created company platforms are used most of the time to inform each other about collisions, at $38 \%$ and $34 \%$, respectively, and data exchange within software is used slightly less, at $28 \%$.

The question on how the work on collision is distributed among team members was the "long answer text" question, which means different answers were accumulated. Similar responses were grouped, as shown in Figure 8. If the question was skipped, it was regarded as "No distribution". For the 'other', the answers were grouped as they could not follow one pattern.

Distribution based on the volume of the work, schedule, workload of employees, choice of employees, intermediate control, collision type, and company standards, along with agile methodology, was recorded in "Other". One company noted that the distribution varies from the designed object as well as daily, while another company highlighted that the distribution is achieved through email and verbal communication. It can be seen in Figure 8 that construction companies and design organizations do not have a similar pattern to follow and have difficulties in distributing work with clashes. Nevertheless, the success of the project highly depends on the proper allocation of the work. 


\section{How is the work on collisions distributed among team members?}

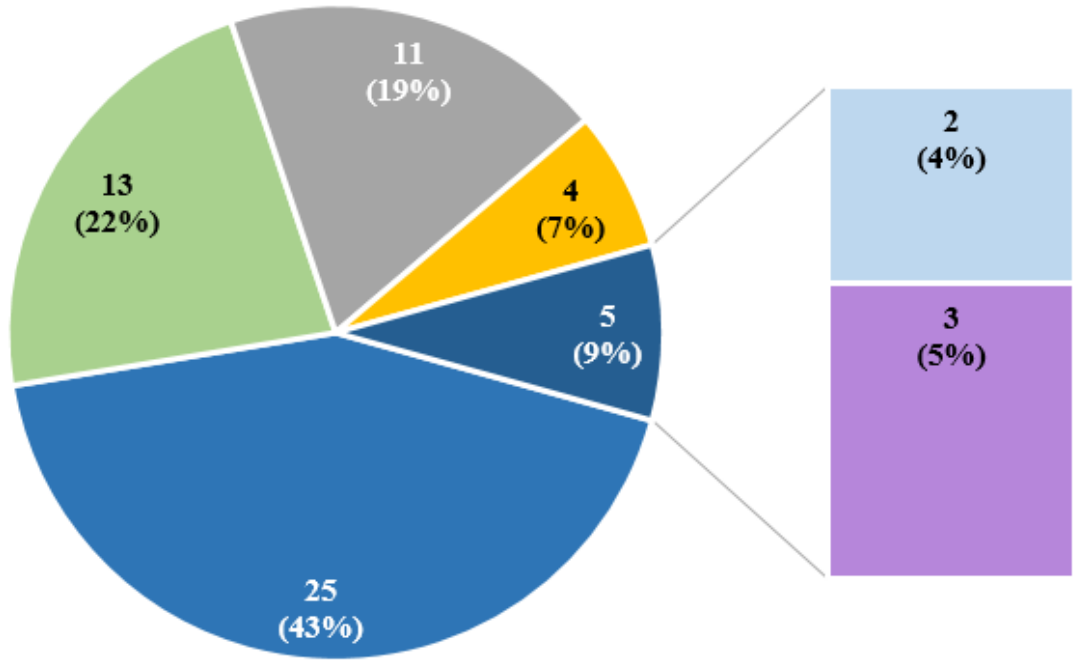

- No distribution

- By employee specialization, responsibility

Group discussion
" Other

- By BIM manager/ Project coordinator

- By project sections

Figure 8. Distribution of work on collisions among team members.

\section{The Results of Interviews-Stage 2B}

The results of the interviews from three organizations enabled a better understanding of Kazakhstan's current situation in the AECO sector of Kazakhstan, identifying the existing gaps and difficulties faced by industry professionals (Table 3).

During the pilot interview with the head of the BIM department (2b), the existing gap with clash detection was found. This construction company $(2 b, c)$ started the integration of BIM technology at the end of 2016. Almost all the projects of this company $(2 b, c)$ are fully BIM integrated. The company created its standards on BIM models that they are required to follow. The following difficulties and concerns were identified related to BIM technology in construction companies during this interview:

- The allocation of detected collision correction between executors;

- Integration of smart technologies into BIM technology;

- The need for information technology specialists in the development of BIM technology in companies.

The process of detecting and resolving the BIM problems was discussed with the next head of the BIM integration department (2c) at the main interviews, and the results of the online survey were also obtained. Based on this interview, the clash detection and resolution process of this company was obtained and illustrated in Figure 9. The output of the interview with the company that does not use BIM technology (3d) identifies the reasons for its rejection. It was found that the possible reason is no requirements by customers and contentment of working with 2D drawings. These reasons were also documented in the research done by Tatygulov et al. [12]. As noted in this investigation (Figure 10), one of the reasons for rejecting BIM is the lack or absence of a regulatory framework for BIM processes. Aitbayeva and Hossain [11] also highlighted the lack of clear guidelines for the implementation of BIM. Nevertheless, there are twelve publicly available published documents regarding BIM technology in Kazakhstan (Figure 1). Based on concerns identified through the online survey and interviews with industry professionals about BIM technology, the researchers reviewed each document in Kazakh and Russian languages. The following issues were identified: 
- The words have been wrongly translated in the context as the words were directly translated to Russian (the translation to the Kazakh language was correct);

- Typos;

- Not readable figures and others.

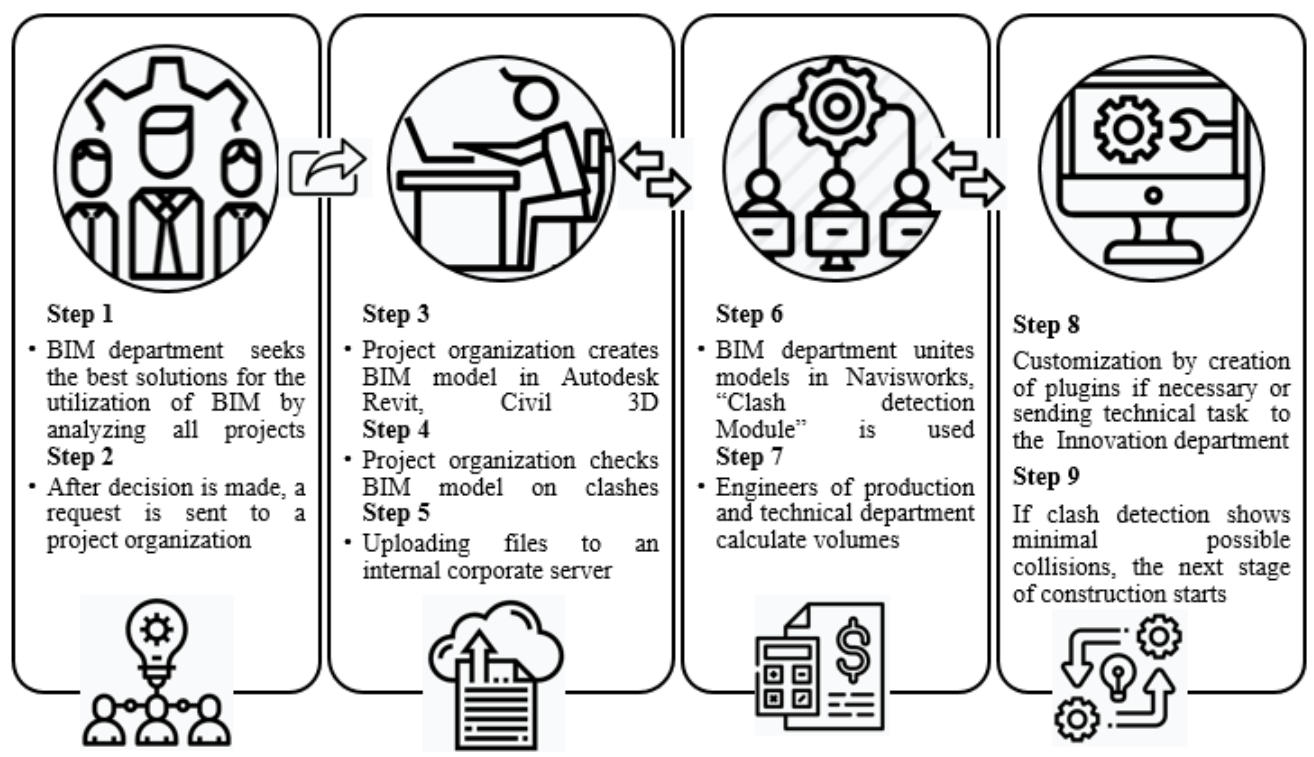

Figure 9. Clash detection and resolution process.

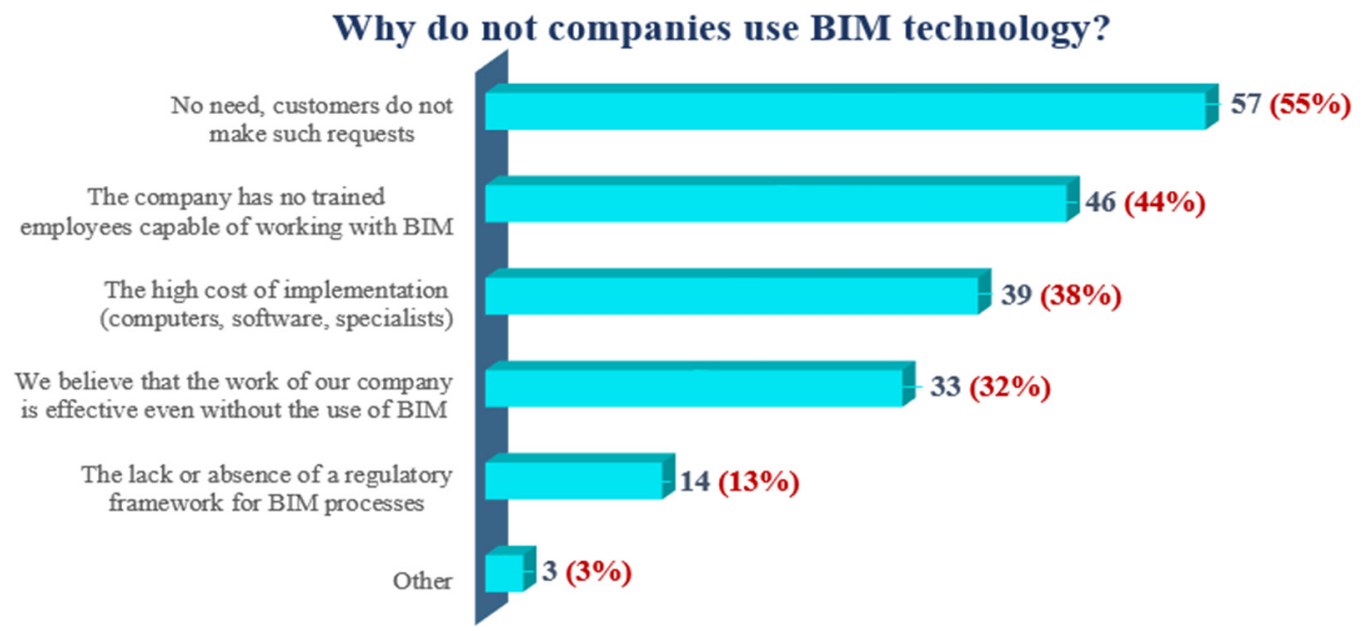

Figure 10. The reasons for refusing to implement BIM among the companies surveyed. (Adapted with permission from ref. [12]. Copyright 2020 National Association of Designers of the Republic of Kazakhstan).

The output of the interview with the head of the modeling center of KazSRICA JSC (1a) revealed some difficulties with translation from English and Swedish standards, in which varieties of definitions required deep analysis. Moreover, as there are not much data regarding BIM-enabled clash detection and resolution processes in the BCRRs of the RK, the need for the development of a standard for clash detection and resolution was also admitted. According to the respondent, construction companies should achieve better "collision avoidance". However, the main reasons for the occurrence of the clashes were ranked differently from the results obtained from the online survey. By using different file formats and insufficient object model information, the objects' complexity was regarded as the secondary reason. Modeling errors, using 2D rather than 3D, lack of qualified specialists, lack of time during the design stage, communication problems between team members, 
and lack of information on BIM technology within the company were regarded as the main reasons for clash occurrence. Improving coordination in shared data environments and training and educational courses for team members were regarded as the most effective strategy to improve the detection and prevention of clashes.

\section{Discussion}

It became apparent that BIM technology has mostly started to be used in recent years in Kazakhstan after the governmental initiatives. However, some companies have been using this technology for more than three years, but they are very few in number. Based on the literature review and comparison of the results of three different studies, it has been evident that, since 2017, the use of BIM in Kazakhstan's construction companies has increased quite noticeably.

As this research focuses on managing work within BIM departments, it was crucial to identify the existence and functionalities of BIM departments. However, this research did not focus on project implementation methods in company practices. As noted in the research done by Akhanova and Nadeem [10], the integrated project delivery method is not the practice of the AECO sector in Kazakhstan. Most of the time, construction companies use design-bid-build and design-build methods [10]. The online survey showed that more than half of companies and organizations have BIM departments. However, the number of employees in departments where BIM technology is used is less than ten, which demands a fast response of Kazakhstan's AECO industry to the adoption of this modern technology.

Although most companies work in "open space", the share of companies working in "isolation from each other" was found to be quite noticeable. Considering that the current literature identifies work in isolation of team members as the main reason for collisions in BIM MEP systems, companies and organizations might be in an inferior position. However, the respondents ranked "Communication problems between team members" as the secondary reason for clash occurrence. Therefore, construction companies and design organizations may not understand the reason for the high number of collisions. It has been found that the use of emails for information exchange and specially created company platforms are utilized most of the time, and security measures during collaborative design are mostly not tracked, which might possibly lead to financial and legal issues in the future if not regulated.

Additionally, it has been found that BIM departments in Kazakhstan are mostly multidisciplinary or converge. The share of interdisciplinary departments was only 10\%. Insufficient coordination with regulation by multidisciplinary project teams could harm current construction delivery and design practice. Based on inherent knowledge and experience, multidisciplinary project teams solve clashes differently, leading to inconsistencies [4]. Therefore, multidisciplinary departments might face additional obstacles during the working process.

The investigation has shown that more than eighty percent of companies have less than ten projects being modeled using BIM technology. Considering that the participating companies and organizations are small enterprises, we can regard small enterprises as more open to implementing modern technology, and they respond faster to industry innovations. Although construction companies and project design organizations use BIM technology to model and visualize buildings and structures, it is also used for calculation and analysis, collision detection, and coordination. However, it was found that no standard would regulate the processes of clash detection and resolution that construction companies and design organizations would like to have. Additionally, concerning construction companies' attendance to search for industry issues and existing gaps, the criticism of the current regulatory documents regarding BIM was noted and further investigated in the online survey. Companies and organizations highlighted in the survey that the current regulatory framework does not correspond to the desired quality. The share of companies that follow BCRRs on BIM and the share of non-regulation regarding BIM by companies and 
organizations are almost equal. Therefore, it is a rather sensitive issue that needs to be addressed by the responsible parties.

The main reasons for the appearance of clashes are the use of different file formats, the lack of time during the design stage, insufficient information about the object model, and the complexity of the modeled objects. The former reason might be explained by companies not following one neutral interoperable standard such as IFC. Insufficient object model information might be because of not developing the level of detail (LOD). Another two reasons, along with a bias in tracking security measures, for the occurrence of clashes in structural objects might be explained by the scarcity of experience in BIM. The reasons for clash occurrence obtained from the online survey and the online interview with the head of information modeling center of the KazSRICA JSC differ noticeably. The reasons mentioned above were placed as secondary ones by the respondent. Therefore, it is essential to obtain feedback before and after the publication of documents on BIM technology to find inconsistencies.

Companies were found to admit that the measure of avoidance of conflicts is more important than detection of conflicts, and the suggested strategies show the right direction for further development. Moreover, the clash coordination meetings are conducted in most companies at the frequency of once a week, indicating the importance of clash identification.

Respondents of the online survey and the head of the modelling center of the KazSRICA JSC regarded educational courses and training of personnel as the most effective strategy to improve clash detection and prevention. However, the lack of qualified specialists was regarded as the secondary reason for the occurrence of conflicts in BIM tools. Therefore, there are some contradictions. The representative of the research institute also highlighted improving coordination in a shared data environment. During an interview with an industry professional who has not implemented BIM into organizational processes yet, resistance to change was noticed owing to contentment using $2 \mathrm{D}$ technology. The reasons for not implementing BIM were surveyed in the literature $[10,11]$, as well as by the National Association of Designers of the Republic of Kazakhstan in collaboration with the KAZGOR Design Academy [12]. However, no practical solutions were found in all three studies.

The survey revealed that most companies do not have the exact collision distribution of the work on collisions that prove the concerns encountered during the meeting with the heads of the BIM department. This could be because there is no standard for clash detection and prevention. The BIM technology allows for working remotely without any difficulties, which respondents pointed out.

\section{Conclusions}

Although Kazakhstan's AECO industry has just entered the BIM environment, this research has shown that BIM-enabled clash detection and resolution processes in construction companies and design organizations are trying to evolve in parallel. However, the regulatory framework is not developed, especially for the detection and resolution of conflicts. Therefore, industry professionals are forced to solve issues that arise without the documentation support they complain about. Furthermore, current regulatory documents on BIM technology in Kazakhstan are error-prone, highlighted in online surveys and interviews.

This research conducted a literature review and review of current regulatory documents regarding BIM technology, interviews with industry professionals, and survey among construction companies and design organizations to investigate whether there are BIM departments (their types and functionalities), coordination meetings for clash resolution, strategies to improve clash detection, and data security measures during collaborative design. Information exchange regarding clashes in projects and distribution of the work on collision among team members was also investigated. The main reasons for clash occurrence and the place of clash occurrence in BIM tools were examined. The following conclusions can be drawn: 
- $\quad$ BIM technology has mostly started to be in use in the recent three years, which shows a fast reaction of Kazakhstan's AECO industry to modern technology. Small-sized enterprises are more interested in adopting BIM technology;

- $\quad$ BIM-enabled clash detection is used even if there is no regulatory standard;

- The main reasons for clashes in the BIM tools of the AECO sector of Kazakhstan are the use of different file formats, lack of time during the design stage, insufficient object model information, and the complexity of the modeled objects. However, the responsible party who had developed regulatory documents regarding BIM technology placed the above reasons as secondary.

- The current literature found that work in isolation of team members is the main reason for collisions in BIM MEP systems. This research revealed that almost half of the team members of construction companies and design organizations surveyed used to work in isolation from each other before the COVID-19 pandemic. Considering that, during the pandemic, most of the time, BIM users worked from home, the number of clashes in MEP systems might increase not only in Kazakhstan, but also worldwide;

- Although construction companies and design organizations admit that the measure of clash avoidance is more important than clash detection, the transition from clash detection to clash avoidance is not possible in a country where standards for clash detection and resolution are not developed;

- Educational courses and training of personnel are the most effective strategy to improve clash detection and prevention;

- There is a bias in terms of tracking security measures during collaborative design;

- As construction companies are not following one neutral interoperable standard, they face difficulties during data exchange. It is recommended to choose one to decrease the working load on BIM project teams;

- Conflict coordination meetings are held in most companies that indicate the importance of clash identification and resolution. However, most companies do not have the exact distribution of the work on collisions among team members.

The responsible party has developed twelve codes of rules and guidelines since 2017. There is no plan to release clash detection and resolution standards on the agenda, as the focus is on creating a BIM-oriented classifier for the CIS countries based on information obtained from the online interview. However, the aim needs to be in delivering clash-free BIM models.

Even if BIM technology is not fully integrated in Kazakhstan and clash detection using BIM is not yet in organizational practice, BIM technology created new job positions, and the necessity for specialists that will be able to analyze and interpret clashes is not far from being reality, which was revealed during online surveys and interviews with industry professionals. There were no previous investigations done on the topic of clash detection management in Kazakhstan. This research contributes information on BIMenabled clash detection in Kazakhstan to the existing body of knowledge. Kazakhstan's AECO industry should use BIM to its full potential, including developing clash detection and resolution processes. It is highly crucial for each country to have well developed documental assistance to avoid nonvalue-adding steps.

\section{Limitations}

In this research, the first and foremost constraint was the COVID-19 pandemic that negated participatory action research in the construction company. As physical presence was restricted, the case study was not conducted. Moreover, because of the pandemic, it was difficult to contact company specialists to ask to participate in the online survey and interviews, as many employees worked remotely and personal contacts were not accessible. However, the social network 'LinkedIn' helped find specialists working with BIM technology, and the survey was sent successfully. It is important to note that the analysis made from the data collected can lead to conclusions that may not represent the reality of the sector. 


\section{Future Work}

As one of the most important reasons for rejecting the use of BIM, based on previous research conducted by the RK National Association of Designers in collaboration with the KAZGOR Design Academy [12], is the high cost of implementation, it is suggested to conduct a cost-benefit analysis in the real case study in Kazakhstan to justify the use of BIM and to obtain further documented proof for construction companies and design organizations. Moreover, there is a need to prove the value added to the projects using BIM-enabled clash control for those companies that have already used it for clash control. Chahrour et al. [3] developed a schema that could be used to perform a cost-benefit analysis of the detection and resolution of BIM-enabled design conflicts in Kazakhstan, as there are no limitations in geography or legal acts. Automation of the clash detection management by creating extra plugins also needs to be addressed in the future. As the scarcity of training centers is highlighted for the third time in the research context, it is important to investigate the existence of training centers and universities where BIM is taught in each city of Kazakhstan and further development schemes.

Supplementary Materials: The online survey and the results are available at https://docs.google. com/forms/d/1hfN4-FvmU2CkTtx3JF58x-g2Q3ro_EUcGSZNtXhc83c/edit and https://docs.google. $\mathrm{com} /$ forms/d/19u3cLBMhRXROmqVLm66xEHHPkSRBsWgj5MWRsFWLysE/viewanalytics, all accessed on 17 November 2021.

Author Contributions: Conceptualization, B.A.; formal analysis, B.A.; funding acquisition, A.N. and J.R.K.; investigation, B.A.; methodology, B.A.; project administration, A.N.; resources, A.N.; supervision, A.N. and J.R.K.; validation, B.A.; visualization, B.A.; writing—original draft, B.A.; writing-review \& editing, A.N. and M.A.H. All authors have read and agreed to the published version of the manuscript.

Funding: This research was supported by the Nazarbayev University Research Fund under Grant \#SOE2017004 and Nazarbayev University Competitive Grants Program (Funder Project Reference: 021220FD2251, Project Financial System Code: SEDS2021022. The authors are grateful for this support. Any opinions, findings, and conclusions, or recommendations expressed in this material are those of the author(s) and do not necessarily reflect the views of Nazarbayev University.

Informed Consent Statement: Informed consent was obtained from all subjects involved in the study.

Acknowledgments: We would like to express our honest gratitude to the heads of construction companies for their professional support and willingness to help find overlooked areas based on industry needs and their helpful assistance in describing the company's processes of clash detection in the company. We would like to show our honest gratitude to the "Kazakh scientific research and design institute of construction and Architecture" for their help in explaining how Kazakhstan started to integrate BIM technology and for shared presentations as additional data for the research. We would like to show our honest gratitude to the National Association of Designers of the Republic of Kazakhstan for their help with sharing information regarding the survey they conducted in 2020 on the topic of "Level of BIM Development and applying in Design and Engineering Survey Companies in the Republic of Kazakhstan".

Conflicts of Interest: The authors declare no conflict of interest.

\section{References}

1. Kubba, S. Green Project Requirements and Strategies. In Green Construction Project Management and Cost Oversight; Elsevier/Architectural Press: Burlington, VT, USA, 2010; pp. 71-111.

2. Pärn, E.A.; Edwards, D.J.; Sing, M.C.P. Origins and probabilities of MEP and structural design clashes within a federated BIM model. Autom. Constr. 2018, 85, 209-219. [CrossRef]

3. Chahrour, R.; Hafeez, M.A.; Ahmad, A.M.; Sulieman, H.I.; Dawood, H.; Rodriguez-Trejo, S.; Dawood, N. Cost-benefit analysis of BIM-enabled design clash detection and resolution. Constr. Manag. Econ. 2020, 39, 55-72. [CrossRef]

4. $\quad \mathrm{Hu}$, Y.; Castro-Lacouture, D.; Eastman, C.M. Holistic clash detection improvement using a component dependent network in BIM projects. Autom. Constr. 2019, 105, 102832. [CrossRef]

5. Akponeware, A.O.; Adamu, Z.A. Clash detection or clash avoidance? An investigation into coordination problems in 3D BIM. Buildings 2017, 7, 75. [CrossRef] 
6. Hsu, H.C.; Chang, S.; Chen, C.C.; Wu, I.C. Knowledge-based system for resolving design clashes in building information models. Autom. Constr. 2020, 110, 103001. [CrossRef]

7. Staub-French, S.; Khanzode, A. 3D and 4D Modeling for Design and Construction Coordination: Issues and Lessons Learned Available online: http:/ / www.itcon.org/2007/26 (accessed on 10 January 2021).

8. Tommelein, I.D.; Gholami, S. Root causes of clashes in building information models. In Proceedings of the IGLC20: 20th Annual Conference of the International Group on Lean Construction, San Diego, CA, USA, 18-20 July 2012. Available online: https:/ /iglc.net/Papers/Details/850 (accessed on 20 January 2021).

9. Kazakh Scientific Research and Design Institute of Construction and Architecture (KazSRICA) Joint-Stock Company (JSC). Available online: https:/ / kazniisa.kz/index.php/timso/1 (accessed on 21 February 2021).

10. Akhanova, G.; Nadeem, A. Current State of Building Information Modeling (BIM) and Total Building Commissioning and study of their applicability in Kazakhstan. In Proceedings of the 33rd CIB W78 Conference 2016, Brisbane, Australia, 31 October-2 November 2016. Available online: https:/ /itc.scix.net/pdfs/w78-2016-paper-006.pdf (accessed on 4 December 2020).

11. Aitbayeva, D.; Hossain, A. Building Information Model (BIM) Implementation in Perspective of Kazakhstan: Opportunities and Barriers. J. Eng. Res. Rep. 2020, 14, 13-24. [CrossRef]

12. Tatygulov, A.A.; Gizatulina, A.S.h.; Zhamankulov, A.M. Level of BIM Development and Applying in Design and Engineering Survey Companies in the Republic of Kazakhstan. Research Results. Bull. Natl. Eng. Acad. Repub. Kazakhstan 2020, 4, 100-106. [CrossRef]

13. Ciribini, A.L.C.; Mastrolembo Ventura, S.; Paneroni, M. Implementation of an interoperable process to optimise design and construction phases of a residential building: A BIM Pilot Project 2016. Autom. Constr. 2016, 71, 62-73. [CrossRef]

14. Van Den Helm, P.; Böhms, M.; Van Berlo, L. IFC-based clash detection for the open-source BIMserver. In Proceedings of the EG-ICE 2010 - 17th International Workshop on Intelligent Computing in Engineering, Nottingham, UK, 30 June-2 July 2010. Available online: https:/ / repository.tno.nl/ / islandora/object/uuid:7f92d278-692b-46ce-8678-92406fa6627c (accessed on 8 January 2021)

15. Hu, Y.; Castro-Lacouture, D.; Eastman, C.M.; Navathe, S.B. Automatic clash correction sequence optimization using a clash dependency network. Autom. Constr. 2020, 115, 103205. [CrossRef]

16. Wang, L.; Leite, F. Knowledge Discovery of Spatial Conflict Resolution Philosophies in BIM-Enabled MEP Design Coordination Using Data Mining Techniques: A Proof-of-Concept. Comput. Civ. Eng. 2013, 419-426. [CrossRef]

17. Wang, L.; Leite, F. Formalized knowledge representation for spatial conflict coordination of mechanical, electrical and plumbing (MEP) systems in new building projects. Autom. Constr. 2016, 64, 20-26. [CrossRef]

18. Hu, Y.; Castro-Lacouture, D. Clash Relevance Prediction Based on Machine Learning. J. Comput. Civ. Eng. 2019, $33,04018060$. [CrossRef]

19. Lin, W.Y.; Huang, Y.-H. Filtering of Irrelevant Clashes Detected by BIM Software Using a Hybrid Method of Rule-Based Reasoning and Supervised Machine Learning. Appl. Sci. 2019, 9, 5324. [CrossRef]

20. Nawari, N.O. Building Information Modeling: Automated Code Checking and Compliance Processes, 1st ed.; Taylor \& Francis Group: Boca Raton, FL, USA, 2018; pp. 50-59.

21. Lévy, F.; Ouellette, J.W. BIM for Design Firms: Data Rich Architecture at Small and Medium Scales; John Wiley \& Sons: Hoboken, NJ, USA, 2019.

22. Hartmann, T. Detecting Design Conflicts Using Building Information Models: A Comparative Lab Experiment. In Proceedings of the CIB W78 2010: 27th International Conference, Cairo, Egypt, 16-19 November 2010. Available online: https:/ /itc.scix.net/ pdfs/w78-2010-57.pdf (accessed on 11 December 2020).

23. Arayici, Y.; Egbu, C.; Coates, P. Building information modelling (BIM) implementation and remote construction projects: Issues, challenges, and critiques. ITcon 2012, 17, 75-92.

24. Porwal, A.; Hewage, K.N. Building Information Modeling (BIM) partnering framework for public construction projects. Autom. Constr. 2013, 31, 204-214. [CrossRef]

25. Wang, L.; Leite, F. Comparison of Experienced and Novice BIM Coordinators in Performing Mechanical, Electrical, and Plumbing (MEP) Coordination Tasks. In Proceedings of the Construction Research Congress 2014, Atlanta, GA, USA, $19-21$ May 2014. [CrossRef]

26. Kensek, K.; Noble, D. Building Information Modeling; John Wiley \& Sons Inc.: Hoboken, NJ, USA, 2014.

27. Cronbach, L.J. Coefficient alpha and the internal structure of tests. Psychometrika 1951, 16, 297-334. [CrossRef]

28. Nunnally, J.C.; Bernstein, I.H. Psychometric Theory; McGraw-Hill Companies: New York, NY, USA, 1994.

29. Ferretti, G.; Keiblinger, K.M.; Zimmermann, M.; Di Giuseppe, D.; Faccini, B.; Colombani, N.; Mastrocicco, M. High resolution short-term investigation of soil CO2, N2O, NOx and NH3 emissions after different chabazite zeolite amendments. Appl. Soil Ecol. 2017, 119, 138-144. [CrossRef]

30. Chan, E.H.; Qian, Q.K.; Lam, P.T. The market for green building in developed Asian cities-The perspectives of building designers Energy Policy 2009, 37, 3061-3070. [CrossRef] 